\title{
Feasibility study on innovative energy-saving technologies in poultry farming
}

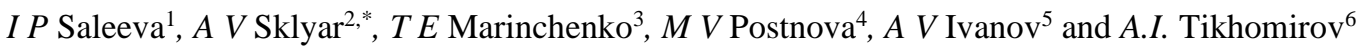 \\ ${ }^{1}$ Federal State Budget Scientific Institution Federal Scientific Center "All-Russian Research and Technological Poultry Institute" of \\ Russian Academy of Sciences (the Federal Science Center "VNITIP RAS") (10 Ptitsegradskaya, Sergiev Posad, Moscow Region \\ 141311, the Russian Federation) \\ ${ }^{2}$ Big Dutchmen LLC (32A Khoroshevskoe highway, Moscow 123007, the Russian Federation) \\ ${ }^{3}$ Federal State Budgetary Scientific Institution (Rosinformagrotekh FSBSI) (Pravdinsky Township 141261, Moscow Region, the Russian \\ Federation) \\ ${ }^{4}$ Volgograd State University (100 avenue Universitetsky, Volgograd 400062, the Russian Federation), Phone: +7-927-254-52-37. \\ ${ }^{5}$ Smena Breeding and Genetic Center, the Federal State Budgetary Scientific Institution (village of Bereznyaki, Sergievo-Posadsky \\ District, Moscow Region) \\ ${ }^{6}$ Ernst All-Russia Research Institute for Animal Husbandry - Federal Science Center, Federal State Budgetary Scientific Institution (Ernst \\ VIZh FSC FSBI) (60 Dubrovitsy, Podolsk Municipal District, 142132, Moscow Region, the Russian Federation)
}

\begin{abstract}
The feasibility study on the effectiveness of locally and generally room livestock population heating at typical poultry houses through a joint radial convection heating system using dark infrared irradiators has been performed. The results of the thermal imaging survey of the heat insulation of poultry houses are presented. The efficiency of the combined heating system and thermal audit of poultry houses for their repair is confirmed by the practice of introducing them in a number of poultry farms.
\end{abstract}

\section{Introduction}

In the poultry industry, infrared (IR) heating began to be introduced with the creation of a system of industrial poultry farms (PF) [1]. The GIIV-2 gas burners and IKZK-215-225-250 infrared lamps were used instead of the BP-1A electric brooders. Gas was cheaper against electricity; in the second case, the lamp compactness was more advantageous than brooder and the "utility" of the IR spectrum was more profitable for poultry. However, the specificity of poultry house heating is such that it requires not only the heating of the individuals themselves, but also heat for heating the constantly changing air of the house due to $\mathrm{CO} 2$ exhaled by poultry. While IR radiation and the air are heated only by reflected heat, therefore, the tasks can be solved only using combined (radial convective, 2D) heating at a poultry house [2]. It should be noted that the thermodynamic conditions change with poultry age and seasonality [3], namely, heat dissipation of individuals, their need for heat and the absorption coefficient of infrared radiation, the level of building aeration, air humidity, etc. (for example, heat generation increases 1.94 times, aeration for the heating season increases $7 \ldots 9$ times). The issues of convective heat transfer from local sources (including IR) were investigated in several studies $[4,5,6]$. The results of these studies are relevant, because the latter have been performed for confined spaces considering their rectangular shapes and conjugate heat transfer. That is to say, these results apply to features of the most industrial buildings with local heating of working areas and a certain aeration of premises. Materials for the analysis of variability of the thermodynamic parameters using infrared sources [7] taking into account this factor in the emissivity measurement methods [8] and in the calculation of complex heat transfer [9] represented in these studies are the basis for calculations for improving the IR heating and efficient introducing joint heating systems [10].

\section{Materials and methods}

The study is based on the feasibility (design) studies, which formed the basis of the experimental part, i.e. a large-scale production checks of radial-convective heating systems in houses and monitoring the state of thermal insulation in the enclosures of houses on the basis of KrasnoroBor CJSC (Tula Region, Leninsky District, Rassvet settlement), in 2012, and DAMATE Group (Penza Region at turkey meat production facilities) in 2017.

\section{Results}

According to our calculations, Krasnobor (Tula) and DAMATE Group (Penza) poultry farms have mounted and operated combined systems using gas dark IR heaters at the poultry houses. Table $1 *$ shows the results

* Corresponding author: alexbd2006@ mail.ru 
of the feasibility study on the effectiveness of their operation in terms of a poultry farm.

The objective difficulty in using infrared heat inside a poultry house is that it is necessary to heat not only poultry, but also significant amounts of inflow. However, infrared rays heat air poorly. Contribution to the solution of this problem is only that during the heating season aeration is minimal. Power of radiative component was selected such as to provide heat not only to meet the livestock needs, but also to heat the fresh air. To do this, it is sufficient that the free convective heat [4] is carried by air heated by the reflected infrared heat and by heat excess from poultry and moved to the middle and upper areas of the poultry house. Outside air jets are thrown in the same zones through the inlets of the longitudinal walls, where the air is preheated (calculations were performed based on the coldest regulatory 5-day). The thermogram represented below (Figure 1) made in one of these poultry houses in the center of the longitudinal wall shows a number of such inlets (wickets with flaps) for fresh air.

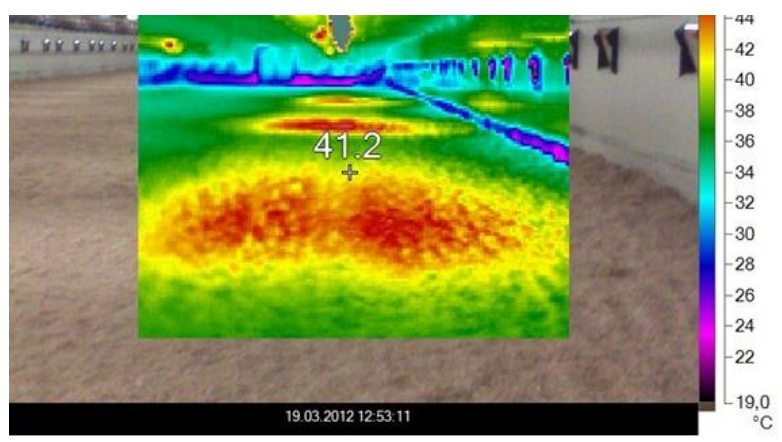

Fig. 1. Thermogram.
The thermogram shows a part of the poultry house with three activated infrared heaters when the room is heated up before poultry is placed. Thermal zones (the temperature level corresponds to the image colors) for each installation have such size that only two sources are sufficient to heat the entire population of the hall for the starting period. It should be noted that the thermal imagers when using the new gas radiating and convective IR heating systems for poultry houses are extremely important as a working tool for adjusting such heating systems.

We have performed thermal imaging monitoring of 43 poultry houses in the mentioned poultry farms. The thermogram bright blue floor stripe shows a heat leakage having an area of up to $105 \mathrm{~m}^{2}$.

Table 2 summarizes the feasibility study results of the heat supply of this poultry house.

Warming the ground floor pays back in 1.63 years, which is quite acceptable, but it would be cheaper and faster to apply PU foam, since isocyanate and polyol for polyurethane foam are available.

\section{Discussion}

An important link in the justification of the possibility of widespread use of infrared heating sources are the studies of biologists [11] on the permissible levels of such exposure to poultry and human health to be introduced into technological standards. The practice of using gas IR burners in the poultry industry $[12,13]$ has showed that such heating provides a stable profit, but for several reasons the open flame heaters are banned for workshop buildings (including for the fire hazard and

Table 1. Feasibility study on the effectiveness of combined systems operation in terms of a poultry farm.

\begin{tabular}{|c|c|c|}
\hline Items o equipment and energy costs & CAPEX, mln rubles & Current expenses, mln rubles \\
\hline Set of BP-1B brooders (68 units) & 0.884 & \\
\hline Electricity for BP-1B (per year) & & 0.713 \\
\hline Gas air heaters GP-95 (6 units) & 1.005 & \\
\hline Gas for GP-95 (per year) & & 0.799 \\
\hline VN40ST infrared heaters (14 units) & 0.03 & \\
\hline Gas for VN40ST (per year) & & 0.931 \\
\hline Total: BP-1B +GP-95/BH40ST & $1.889 / 1.03$ & $1.512 / 0.931$ \\
\hline \multicolumn{3}{|c|}{$\begin{array}{l}\text { * Notes: } \\
\text { 1) BH40ST payback period is } 1.03 /(1.512-0.931)=1.77 \text { years; } \\
\text { 2) Only } 2 \text { units for the starting heating are working at the aft end of the poultry house; the rest of the poultry house uses an } \\
\left.\text { energy saving mode all } 3 \text { weeks of each cycle at a temperature of } 14 \ldots 18{ }^{\circ} \mathrm{C} ; 3\right) \text { in the rest of the period from } 3 \text { weeks to the } \\
\text { end of fattening; the combined IR heating system provides heat savings due to the lowered background temperature in the } \\
\text { middle and upper part of the poultry house while maintaining the rated bedding temperatures; } \\
\text { 4) The calculations are made at prices: Vertyazin, Sibshvank and Roberts Gordon. }\end{array}$} \\
\hline
\end{tabular}

Table 2. Feasibility study results of the heat supply of the poultry house

\begin{tabular}{|c|c|c|}
\hline Indicators & Units & Values of indicators \\
\hline $\begin{array}{c}\text { Heat losses during one heating season in areas of poor } \\
\text { heat insulation of the poultry house }\end{array}$ & Gcal & 24.462 \\
\hline Losses due to insulation of 1/35 poultry houses & Ths. rubles & $30.625 / 1071.875$ \\
\hline Cost of repairing insulation of 1poultry house & Ths. rubles & 49.875 \\
\hline Payback period & years & 1.63 \\
\hline
\end{tabular}


insufficient burners protection); this has stimulated the introduction of the closed dark gas infrared heaters.

Those poultry farms that operate dozens of buildings thermal imagers require the regular monitoring of objectively aging premises that are losing their thermal insulation capacity. There are about 17,500 poultry houses at more than 500 poultry farms in the Russian Federation. The level of heat loss through fencing structures varies within $65 \ldots 115 \mathrm{kcal} / \mathrm{h}$ depending on the region and the state of a particular structure. Taking into account the price of $1 \mathrm{Gkal}$, the poultry industry of the Russian Federation hourly loses up to 1.75 million rubles due to poor thermal insulation of poultry houses and "warms" the atmosphere by 2,000 Gcal. Thermal imaging monitoring legitimately legalized by the standard [14] and detailed recommendations for its implementation [15] in terms of surveying the state of buildings, structures and equipment.

\section{Conclusions}

Infrared heating allows saving the energy resources, which are becoming more expensive every year increasing the cost of poultry. The introduction of gas radiation-convective dark infrared heating systems for outdoor poultry houses is economically profitable (payback period is 1.77 years). The capacity of the abovementioned heaters should be calculated based on the rated coldest 5-day radial component for heat supply to the livestock; based on the convection flow heating using reflected IR heat and free heat from poultry (heat consumption is up to $994 \mathrm{Gcal}$ per heating season per broiler house).

The use of thermal imaging monitoring of the state of thermal insulation on thousands of buildings of industrial poultry farms of the Russian Federation should become mandatory for the scheduled repair of these premises, since such costs quickly pay off (1.63 years) and provide a reduction in heat emissions into the atmosphere (up to 92 Gcal per poultry house during the heating season).

\section{References}

1. N.F. Kozhevnikova, The use of infrared radiation in animal husbandry, Light engineering, 5, 6-9 (1978)

2. V.V. Piatachkov, Feasibility of radiation-convective heating systems based on gas infrared emitters, Energy safety and energy saving, 3, 22-4 (2010)

3. V.N. Karpov, Thermodynamics of Radiation Technologies in agribusiness, Scientific Works of VIESKh, 84, 98-109 (1998)

4. G.Yu. Mamontov, Analysis of free convective heat transfer regimes in a closed area when operating infrared emitters, News of RAS. Energy, 5, 37-44 (2014)

5. G.V. Kuznetsov, 2D problem of natural convection in a rectangular area with local heating and heatconducting boundaries of finite thickness, News of RAS. Fluid and gas mechanics, 6, 29-39 (2006)
6. M.A. Sheremet, Conjugated heat transfer in the closed area with a locally concentrated heat source, Engineering Physics Journal, 1, 56-3 (2006)

7. Yu.A. Surinov, On non-stationary problems of the theory of radiative heat exchange, News of Universities. Ferrous metallurgy, 7, 58-66 (1997)

8. V.A. Arkhipov, Analysis of the non-stationary method for measuring the integral emissivity, Thermophysics and Aeromechanics, 19(6), 751-60 (2012)

9. S.A. Krupennikov, Application of the modified zonal method for the calculation of complex heat exchange, News of Universities, Ferrous metallurgy, 5, 46-9 (1995)

10. N.I. Kurylenko, Heat transfer by heating a local area of large-sized production facility with gas infrared emitters, Engineering Physics Journal, 86(3), 48994 (2013)

11. L.A. Gvozdenko, Justification of acceptable standards for irradiation with infrared radiation according to its spectral composition, Occupational Medicine and Industrial Ecology, 12, 13-8 (1991)

12. F.A. Krivitskaya, Energy-saving heating system using gas infrared burners for poultry houses with floor-based poultry, Scientific works of VIESKh, 84, 52-7 (1998)

13. V.V. Shevtsov, Local gas infrared heating in case of floor broiler upkeep: abstract of a thesis of a PhD in Engineering (2002)

14. GOST R 54852-2011 Buildings and structures Method of thermovision control of enclosing structures thermal insulation quality 2012 (Updated: 03/28/2013) (Moscow: STANDARTINFORM) 16 $\mathrm{p}$

15. MDS 23-1.2007 Guidelines for a comprehensive heat engineering examination of external enclosing structures using thermal imaging equipment 2007 (Updated on 11/05/2012) (Moscow: FSUE SRC "Construction" / FSUE TsIPP) $20 \mathrm{p}$ 